\title{
Adapting prospective structural analysis to strengthen sustainable management and capacity building in community-based natural resource management contexts
}

\author{
$\frac{\text { María del Mar Delgado-Serrano }}{5}{ }^{1}, \underline{\text { Pieter Vanwildemeersch }}{ }^{1}, \underline{\text { Silvia London }}^{2,3}, \underline{\text { Cesar E. Ortiz-Guerrero }}{ }^{4}$, Roberto Escalante Semerena $^{2}$ \\ ${ }_{5}^{5}$ and Mara Rojas ${ }^{2,3}$
}

\begin{abstract}
Local communities collectively managing common pool resources can play an important role in sustainable management, but they often lack the skills and context-specific tools required for such management. The complex dynamics of social-ecological systems (SES), the need for management capacities, and communities' limited empowerment and participation skills present challenges for community-based natural resource management (CBNRM) strategies. We analyzed the applicability of prospective structural analysis (PSA), a strategic foresight tool, to support decision making and to foster sustainable management and capacity building in CBNRM contexts and the modifications necessary to use the tool in such contexts. By testing PSA in three SES in Colombia, Mexico, and Argentina, we gathered information regarding the potential of this tool and its adaptation requirements. The results suggest that the tool can be adapted to these contexts and contribute to fostering sustainable management and capacity building. It helped identify the systems' dynamics, thus increasing the communities' knowledge about their SES and informing the decision-making process. Additionally, it drove a learning process that both fostered empowerment and built participation skills. The process demanded both time and effort, and required external monitoring and facilitation, but community members could be trained to master it. Thus, we suggest that the PSA technique has the potential to strengthen CBNRM and that other initiatives could use it, but they must be aware of these requirements.
\end{abstract}

Key Words: Argentina; Colombia; Latin America; local knowledge; Mexico; participatory techniques; social-ecological systems; strategic foresight

\section{INTRODUCTION}

Earth is facing extraordinary environmental challenges. Never in human history have we experienced changes as rapid, large, complex, and potentially catastrophic as those we face today (Flannery 2006). The activities of modern societies, combined with growing human populations, are having increasingly salient direct and indirect impacts on natural systems. Rates of biodiversity loss, water mismanagement, deforestation, and overexploitation of fisheries and other natural resources are higher than ever (MEA 2005). Reversing these trends is imperative, but sound natural resource management requires recognizing that natural ecosystems and human societies cannot be considered separately; instead, they must be considered as linked social-ecological systems (SES; Berkes and Folke 1998, Anderies et al. 2004) that evolve, often in unexpected or nonlinear ways, according to the human and biophysical interactions they receive (Nelson et al. 2007).

Communities that base their livelihoods on and interact daily with ecosystems can play an important role in the sustainable management of SES (Dietz et al. 2003, Cox et al. 2010, Soviana and Kühl 2013). These communities have continuous and often long-term relationships with their environments, and their local knowledge and practices are adapted to the ecological systems in which they live (Berkes and Folke 1998). At the national and international levels, there is a tendency to devolve resource management decisions to the local level. As a result, many common pool resources worldwide are currently managed through so-called community-based natural resource management (CBNRM) strategies. As a theoretical approach, CBNRM has evolved over the past two decades as an alternative to top-down strategies in natural resource management. It has attracted the interest of donors and international institutions (Shackleton et al. 2010), although it is not a panacea (Leach et al. 1999, Berkes 2007). There is no single, accepted definition of CBNRM, but in this research we define it as "the collective management of ecosystems to improve human well-being. It aims to devolve authority for ecosystem management to the local (community) level, thereby empowering communities to manage their own resources without permanently damaging, depleting or degrading them. It therefore requires strong investments in capacity development and the development of local institutions and governance structures" (Fabricius and Collins 2007:85).

CBNRM principles can empower local communities to overcome the inherent biases and limitations of the traditional environmental planning model by incorporating the ideas, knowledge, energy, and assistance of local people (Berkes 2007). However, as highlighted by the definition above, local inhabitants frequently lack the organizational (particularly related to knowledge regarding wise management strategies) and financial resources to achieve proper management (Wiber et al. 2009). Local knowledge can be a valuable asset to sustainable management, but SES are complex systems with high degrees of

${ }^{1}$ Department of Agriculture Economics, Sociology and Policy, Universidad de Córdoba, Spain, ${ }^{2}$ IIESS, UNS-CONICET, ${ }^{3}$ Departamento de Economía UNS, Argentina, ${ }^{4}$ Pontificia Universidad Javeriana, Bogotá, Colombia, ${ }^{5}$ Faculty of Economics, Universidad Nacional Autónoma de México, Mexico 
uncertainty in their dynamics that require additional inputs for sound management and decision making. Strengthening CBNRM decision making requires the following: (1) comprehensive knowledge and common understanding of SES dynamics (Berkes et al. 2000, Ostrom 2007a,b) to analyze different options and predict the results of different management practices; (2) context-sensitive methodologies and tools that capture complexity and permit simulations of different alternatives and their consequences; and (3) adaptable participatory tools that encourage local involvement, promote consensus, and lead to capacity building and social learning (Raymond et al. 2010, Parrott et al. 2012).

To support these requirements, we assessed interest in using prospective structural analysis (PSA) to support local planning and sustainable management in three CBNRM contexts. Prospective techniques were considered because they employ participatory tools that embrace complexity and facilitate the systematic analysis of current and future factors (Godet 1994, European Commission 2014). Strategic foresight methods were initially designed to support public institutions in regional development, i.e., regional foresight (De Jouvenel and Roque 1994, Kelly et al. 2004, Godet 2006, Stratigea and Papadopoulou 2013). These methods have also been used extensively by the private sector, i.e., corporate foresight (Lafourcade and Chapuy 2000, Benassouli and Monti 2005, Chapuy and Gros 2010), where they contribute to firms' strategic management by helping them cope with uncertainty and evaluate alternative perspectives. However, no examples of this technique being applied to CBNRM exist in the consulted literature.

Godet (1986) transformed strategic foresight analysis from an initial philosophical and literary form into a technique that could be operationalized through a variety of quantitative methods (known by the French name of la prospective), which together constitute a toolbox for the implementation of this method (Gómez-Limón et al. 2009). PSA is part of the toolbox of la prospective and one step in the process of scenario-building, another technique proposed by this method (Arcade et al. 1992). Structural analysis is used to structure the ideas describing a system and elicit the roles (actual and future) played by the key variables and drivers in the evolution of the system. It relies upon a process of deliberation conducted through participatory workshops where experts agree on the main variables shaping the system and how they influence each other. These influence/ dependence relationships classify the variables in different clusters that permit understanding the role of each variable (or group of variables) within the system, according to participants' perceptions (Godet 1986). This method can analyze systems with many variables, identify the driving changes, show possible trends and evolution, detect clusters of variables, and describe the strength of relationships and potential influences. The results provide insightful information that can be used to design effective planning and management actions. The objectives of this paper are to present the results of PSA testing in three SES with CBNRM initiatives in Colombia, Mexico, and Argentina, and to analyze (1) the contributions of the method to sustainable management by providing a greater understanding of the SES and informing the decision-making process and (2) the adaptations required to use PSA in CBNRM contexts.

\section{METHODS}

This research was performed in three SES (Figs. 1, 2, and 3), each facing different environmental challenges, including water and biodiversity management, forest management, and fisheries and coastal area management. The study period spanned from June 2013 to September 2014. An international research team was in charge of methodological support and a research team in each country developed the fieldwork. The teams met face-to-face and online several times to make decisions regarding how to adapt the method. The testing of PSA was part of a broader investigation developed by the action research project COMET-LA (Community-based management of environmental challenges in Latin America: http://www.comet-la.eu).

Fig. 1. Location of the Colombian social-ecological system.

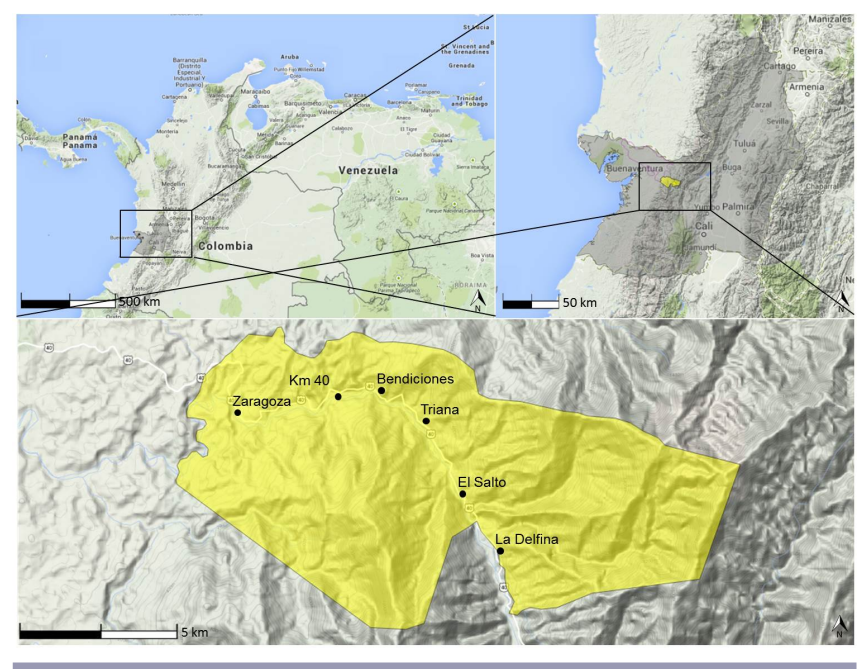

Fig. 2. Location of the Mexican social-ecological system.

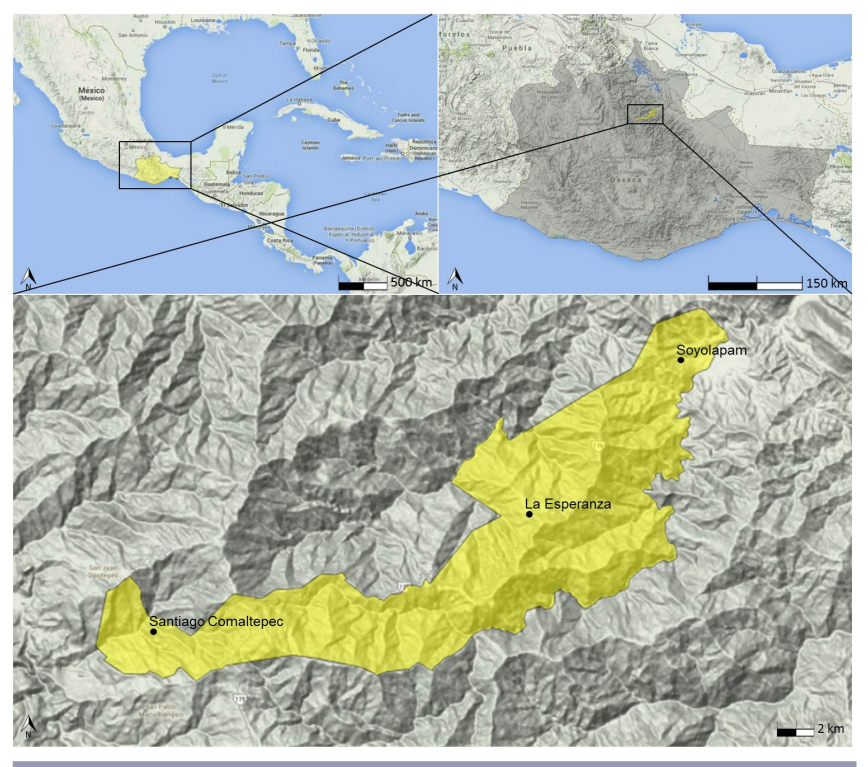


Table 1. Description of the social-ecological systems (SES).

\begin{tabular}{|c|c|c|}
\hline Colombia & Mexico & Argentina \\
\hline \multicolumn{3}{|l|}{ Location } \\
\hline $\begin{array}{l}\text { Chocó Biogeographic region } \rightarrow \text { Pacific coast } \\
\rightarrow \text { Buenaventura } \rightarrow \text { Community Council of Alto y } \\
\text { Medio Dagua }\end{array}$ & $\begin{array}{l}\text { Mesoamerican biocultural region } \rightarrow \text { State of } \\
\text { Oaxaca } \rightarrow \text { Sierra Norte de Oaxaca } \rightarrow \text { Santiago } \\
\text { Comaltepec }\end{array}$ & $\begin{array}{l}\text { Southwestern coast of Buenos Aires region } \rightarrow \\
\text { Bahía Blanca Estuary region and adjacent coast }\end{array}$ \\
\hline
\end{tabular}

Population

1502 Afro-Colombian inhabitants spread across six villages (Zaragoza, Km 40, Bendiciones, Triana, El Salto, and La Delfina)

Main livelihoods

Agriculture, artisanal gold mining, logging, and fishing

Lack of formal jobs

High level of poverty and marginalization

Brief description of the SES

Tropical forest with high biodiversity and abundant water

Closely connected to Buenaventura and Cali cities by a highway road that pass through the territory

Armed conflict and illegal activities (mining, logging)

Aerial spraying of glyphosate to eliminate coca crops

affects health and ecosystems

Incipient ecotourism initiatives

Traditional ecological knowledge and ancestral habits

that privilege conservation over exploitation

Community-based natural resource management (CBNRM)

Communal ownership of the land only recognized since 2005

Incipient CBNRM with internal rules not respected

by external actors

Multilevel governance system with an important role

of the regional and national authorities

Clearly defined extraction and exclusion rights, but

not monitoring or sanctioning

Active participation of women

Rules respected internally but not recognized externally

Community involvement in the research

25 people including current and potential future authorities actively involved in the project and trained as coresearchers
32,582 inhabitants in the municipalities of General Daniel Cerri, Ingeniero White, Pehuén Co, Villa del Mar, and Monte Hermoso

Petrochemical industry, port, artisanal and conventional fishery, tourism, livestock industry (slaughterhouses), fruit and horticulture High level of economic development

Important environmental and cultural resources (e.g., salt marshes and fossil footprints) Pollution (estuary) and nonsustainable use of resources (buildings, sand extraction, dredging, port functioning)

Urban influence

Artisanal fisheries threatened by overexploitation by large trawlers

Lack of territorial identity or ancestral ties to the land (inhabitants are descendent of European migrants)

Natural resources are privately or state-managed. Only artisanal fisheries practise CBNRM

Weak local governance

Different national and regional institutions interact uncoordinatedly creating free-riding opportunities

Actors rely on authorities to solve the management problems

Lack of tradition in collective action

People participate in the different workshops
Communal property rights recognized since 1953 Long history of CBNRM
Local customary rules embedded in state and federal laws, but with internal autonomy for
administrative management
Clearly defined extraction, exclusion, sanctioning,
and monitoring rights
No participation of women
Rules respected internally and externally
1 community member working for the project A group of people commissioned by the General Assembly to be trained in the tool


Table 2. Workshop organization and participant selection.

\begin{tabular}{|c|c|c|c|}
\hline & Colombia & Mexico & Argentina \\
\hline \multicolumn{4}{|l|}{ PSA phases $2 \& 3$} \\
\hline Number of workshops & $\begin{array}{l}5 \text { ( } 2 \text { with coresearchers, } 2 \text { with internal } \\
\text { stakeholders, and } 1 \text { with external } \\
\text { stakeholders) }\end{array}$ & $\begin{array}{l}2 \text { for PSA phase } 1 \text { (internal and } \\
\text { external stakeholders) } \\
3 \text { for PSA phase } 2 \text { (external } \\
\text { stakeholders/ internal men/ internal } \\
\text { women) }\end{array}$ & $\begin{array}{l}1 \text { (internal and external stakeholders } \\
\text { together) }\end{array}$ \\
\hline Duration & 1 day & 5 days & 1 day \\
\hline Participants by gender & 32 men, 37 women & 23 men, 12 women & 15 men, 10 women \\
\hline \multirow{8}{*}{$\begin{array}{l}\text { Selection criteria (internal } \\
\text { stakeholders) }\end{array}$} & Availability & Availability & Capacity of influence \\
\hline & Willingness & Willingness & Direct link to the SES \\
\hline & Legitimacy & Legitimacy & Live in the area of influence \\
\hline & Capacity of influence & Capacity of influence & Representativeness of his/her \\
\hline & $\begin{array}{l}\text { Knowledge of the territory Direct link } \\
\text { to the SES }\end{array}$ & Knowledge of the territory & stakeholder subgroup \\
\hline & Live in the area of influence & & \\
\hline & Coresearchers & & \\
\hline & Gender & & \\
\hline \multirow{6}{*}{$\begin{array}{l}\text { Type of participants (internal } \\
\text { stakeholders) }\end{array}$} & Local authorities & Local authorities & Local authorities \\
\hline & Inhabitants & Inhabitants & Regional authorities \\
\hline & NGOs and local CSOs & & Inhabitants \\
\hline & $\begin{array}{l}\text { Research and environmental } \\
\text { institutions }\end{array}$ & & $\begin{array}{l}\text { Representatives of fishing and tourism } \\
\text { sectors }\end{array}$ \\
\hline & & & Environmental managers \\
\hline & & & NGOs and CSOs \\
\hline $\begin{array}{l}\text { Selection techniques (internal } \\
\text { stakeholders) }\end{array}$ & Stakeholder mapping & Stakeholder mapping & Stakeholder mapping \\
\hline \multirow[t]{2}{*}{$\begin{array}{l}\text { Selection criteria (external } \\
\text { stakeholders) }\end{array}$} & $\begin{array}{l}\text { Representatives of municipal/regional/ } \\
\text { national public sector institutions with } \\
\text { influence in the SES }\end{array}$ & $\begin{array}{l}\text { Representatives of government } \\
\text { institutions with influence in the SES } \\
\text { Academics }\end{array}$ & -- \\
\hline & $\begin{array}{l}\text { NGOs working or with influence in the } \\
\text { SES }\end{array}$ & $\begin{array}{l}\text { NGOs working or with influence in the } \\
\text { SES }\end{array}$ & \\
\hline \multirow{4}{*}{$\begin{array}{l}\text { Type of participants (external } \\
\text { stakeholders) }\end{array}$} & Environmental managers & Representatives of government & \\
\hline & NGOs & institutions & \\
\hline & Representatives of National Ministries, & Academics & \\
\hline & local and regional authorities & NGOs & \\
\hline $\begin{array}{l}\text { Selection techniques (external } \\
\text { stakeholders) }\end{array}$ & Venn diagrams & Stakeholder mapping & -- \\
\hline \multicolumn{4}{|l|}{ PSA phase 5} \\
\hline Number of workshops & $\begin{array}{l}2 \text { ( } 1 \text { with internal and } 1 \text { with external } \\
\text { stakeholders) }\end{array}$ & $\begin{array}{l}4 \text { ( } 1 \text { in each of the } 3 \text { villages and } 1 \text { with } \\
\text { the external stakeholders) }\end{array}$ & $\begin{array}{l}1 \text { (internal and external participants } \\
\text { together) }\end{array}$ \\
\hline Duration & 1 day & 1 day & 1 day \\
\hline Participants by gender & 20 men, 8 women & 87 men 16 women & 12 men, 8 women \\
\hline
\end{tabular}

providing planning and management tools to the local communities, led us to introduce some adaptations. We introduced two additional stages: an initial stage (selection of experts) to identify who might be considered experts in the SES under analysis and a final stage (results analysis and validation) to analyze and validate the results with other community members. The final stage was intended to increase participation and appropriation of the outcomes and to contribute to strengthening CBNRM and capacity building, as a result. Additionally, the technical and abstract PSA language was translated into more understandable lay language. The Colombian research team performed a mock exercise with a group of students to calibrate the technique and adapt it for working with community members. As a result, they developed a methodological guide for PSA adapted to oral cultural dynamics, which should support the communities in replicating the methodology in the future.

\section{Phase 1: Selecting the experts}

PSA is based on experts' opinions; thus, identifying people with a good knowledge of each SES was critical. We used stakeholdermapping techniques to select and categorize potential participants (Reed 2008) and identified various actors internal and external to each SES. We considered local inhabitants involved in CBNRM as internal and people working in organizations with influence in the SES and a deep SES knowledge as external. Our main interest was testing the technique with internal stakeholders, but complementing their views with the perspectives of external stakeholders was considered essential to obtaining comprehensive SES understanding and contributing to capacity building and crossfertilization. Table 2 summarizes the methods used to select the participants and the organization of the workshops.

However, the context-specific characteristics of Mexico and Colombia led us to consider the convenience of hosting separate 
workshops with internal and external stakeholders to facilitate confidence and free speech among the internal stakeholders. In Mexico, language was also an issue because the community's primary language is Chinantec; however, one of the facilitators spoke this language. In both countries, we began phases 2 and 3 by hosting a workshop with the internal stakeholders to give them more freedom to express their views; then, the results were discussed with the group of external stakeholders and community representatives. The external stakeholders added information to the internal stakeholders' analysis, and the latter decided whether the information was relevant or not. In Colombia, two workshops with internal actors were held: one with coresearchers that emphasized how the method works and how the tools and techniques could be used, and another with local stakeholders. In Argentina, splitting the work group was not considered necessary. In all three cases, the groups met several times to develop different phases of the method.

\section{Phase 2: Listing the variables}

This PSA phase consists of compiling a list of the most relevant variables in the system. This technique can handle several dozen variables, even if high numbers complicate the subsequent steps. The final list is decided by consensus, and each variable must be clearly defined, characterized, and understood by all participants.

PSA's practical and theoretical principles were explained before starting each workshop. To help select the variables, the teams presented a previous characterization of each SES, developed using an adapted version of the SES framework (Ostrom 2009) with more than 100 variables (Delgado-Serrano and Ramos 2015). These characterizations were built into each SES in earlier stages of the research (see Avendaño et al. 2013 for Colombia's outcomes, Escalante et al. 2013 for Mexico's, and London et al. 2013 for Argentina's). The characterizations were intended to prompt reflections by providing participants with a broad overview of the SES, but participants were not forced to choose between the included variables.

Facilitators asked the participants to list the most relevant variables that answered the following question: Which issues and matters are relevant to the management of the central environmental challenges (water, biodiversity, forest, fisheries and coastal management) in our SES? To help clearly define, characterize, and provide understanding of each variable for all participants, the information was gathered in a template that included the name, a full description, and a classification as internal or external, depending on whether the variable could be influenced by the community or not.

In the Colombian and Mexican communities, the internal stakeholders elaborated on the initial lists. These lists were then discussed with the external stakeholders, leading to a final list approved by the various participants. In Argentina, the single group of stakeholders made this intermediate step unnecessary.

\section{Phase 3: Describing the relationships between variables}

In this phase, a cross-impact analysis is performed to assess the influences between variables (from 0 , no influence; to 3 , strong influence). A p value could be introduced when the participants envisioned a potential influence if circumstances were to change. These values must be replaced by 0 or 3 in the final matrix (depending on the possibility of these changes occurring) to enable the next analysis, but reflections and discussions focusing on these values are particularly interesting, especially with regard to the SES's future and the decision-making process. The results are represented in an $\mathrm{n} \times \mathrm{n}$ matrix, which is known as the Matrix of Direct Influences (MDI). The sign (positive/negative) of each influence is recorded (to be used in the final analysis) but not introduced in the matrix, because this would make the next analysis impossible.

Facilitators had to emphasize and clearly isolate the real direct influences (and avoid introducing indirect influences through other variables) and distinguish the direction of the influence, e.g., determine which of the two analyzed variables influences the other. The participants agreed on the final strengths of the influences.

\section{Phase 4: Identifying the roles played by the variables}

This PSA phase uses the free software MICMAC (M. Godet, http://www.laprospective.fr/methodes-de-prospective/les-outils-versioncloud/1-micmac.html) to calculate the direct influence and dependence of each variable (the sums of each row and column, respectively). MDI is then raised to the second, third, $\ldots \mathrm{n}^{\text {th }}$ power until the overall ranking of the variables' influence and dependence remains constant. This stable matrix, known as the Matrix of Indirect Influences (MII), establishes the indirect influences between all variables over one, two, ... n-1 variables. It shows the roles of the variables in the medium to long term because more time is typically needed to exert/receive influences through other variables (Godet 1994).

Direct and indirect influence/dependence maps can be plotted, revealing variable clustering. Their positions indicate the different functions the variables play in the system. We used the classification proposed by Delgado-Serrano et al. (2015a): (1) Input variables describe the system and condition its dynamics; they exert a strong influence, but the actions of other variables on them are not transmitted to the system; (2) Stakes variables are both highly influential and dependent, but they are also the most unstable because any influence on them can cascade throughout the rest of the system; (3) Regulator variables have moderate dependence and influence on the system and act as levers; (4) Autonomous variables have low potential to generate changes. Finally, (5) Output variables have low influence but are very influenced by others; thus, they are descriptive indicators of the system's evolution (Fig. 4). These maps show the current and future participants' perceptions of the system and what they consider to be constraints (variables that cannot be influenced), opportunities (variables with medium influence and dependence capacity), and potentialities (variables with high influence and dependence capacity) for change. The comparison between the direct and indirect classifications confirms the importance of certain variables and reveals the role that these variables might play over the longer term. PSA also identified networks or loops of interrelated variables through the construction of influence graphs.

The researchers were primarily responsible for developing this phase, although they were open to sharing the method with interested stakeholders. In Colombia and Argentina, preliminary MICMAC outcomes were shown at the ends of the workshops to increase the participants' ownership and understanding of the results. This created a higher level of familiarity with and confidence in the technique and, thus, higher satisfaction among participants. In Mexico, the analysis was performed later. 
Fig. 4. Clustering of variables according to their influence and dependence.

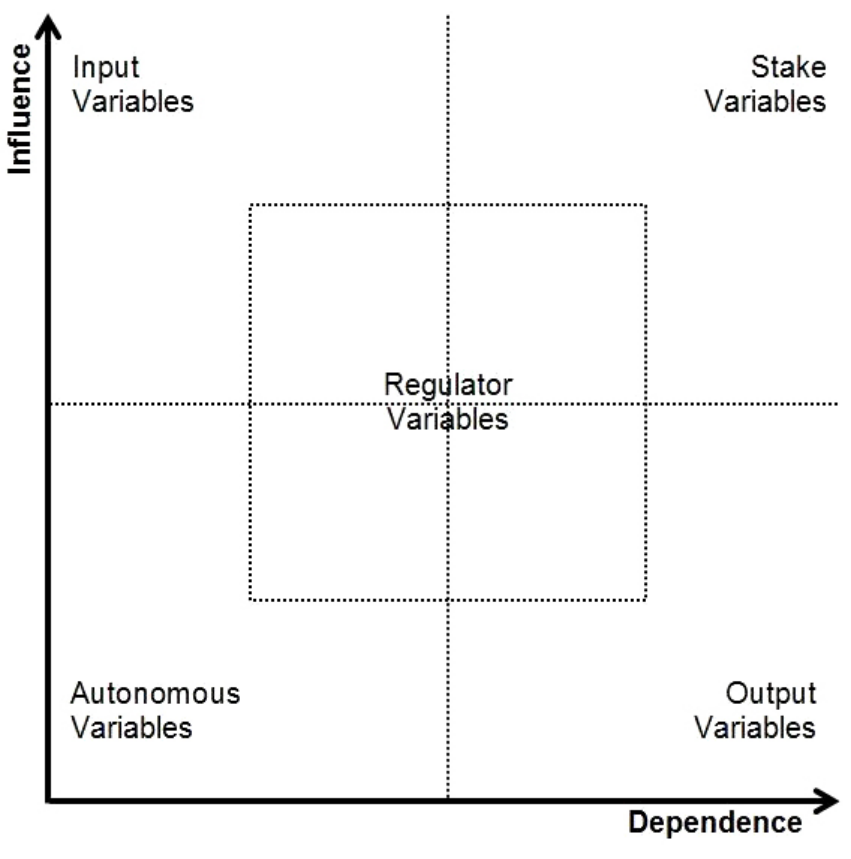

Phase 5: Validating and interpreting the results

After the collected data was processed using MICMAC software, different visualizations, such as influence/dependence maps, and influence graphs and rankings, can be used to understand the roles played by the variables. Rankings based upon the total direct influence of each variable were used in the Mexican and Colombian cases. In Argentina and Colombia, influence graphs were analyzed in detail to extract the most important variables, together with their most important influences, for further analysis.

In Colombia and Mexico, separate workshops were organized with internal and external stakeholders. The validation workshops were open to a broader number of participants to disseminate the results and strengthen the communities' knowledge. Participants reviewed the variables that had been identified and prioritized, discussed the roles played by the different variables in the provided visualizations, and gave feedback on the results. The workgroup's final remarks were analyzed. Special attention was paid to analyzing and interpreting counterintuitive outcomes.

\section{RESULTS}

Table 3 presents the final list of variables for each SES, including both social and ecological variables. The broader audience in phase 5 recognized that the prioritized variables clearly highlighted the main problems faced by each SES. In the Mexican community, most of the variables were internal and linked to CBNRM (e.g., CBNRM unpaid activities, collective choice rules, and the different rights of resource management), its governance system (e.g., governance institutions and property rights systems), and its effects on livelihoods (e.g., migration and economic activities). In the Colombian SES, a moderate number of variables were linked to external influences (e.g., megaprojects, government decisions, and illegal actors) and their effects in the territory (e.g., deforestation, illicit crops, transport externalities, etc.), but others reflected the need to strengthen the community's identity and rules (e.g., ancestral knowledge, community as a social group, and locally fostered research). In the Argentinian analysis, external variables (e.g., industrial poles, dredging projects and external governance of fisheries) were very relevant, but participants also prioritized those variables related to the degradation of natural resources (e.g., pollution, overfishing, and environmental changes in the coasts and estuary).

Figures 5, 6, and 7 show the influence/dependence maps of direct influences. These maps are quite intuitive and represent the function of each variable in the system. Participants generally agreed that these results represented their reality and responded positively to obtaining direct and practical results (variable classification and role identification) after participating in the rather abstract procedure (filling a matrix with $0-1-2-3-p$ ) in the previous workshops. They could also identify those variables for which actions were more effective (regulator and stake variables). Indeed, when intervening in output or autonomous variables, effort will likely be wasted, but when efforts are concentrated on variables with more active roles in the system, the effects can be multiplied through those variables' direct and indirect influences.

Fig. 5. Influence/dependence map for direct influences in Colombia.

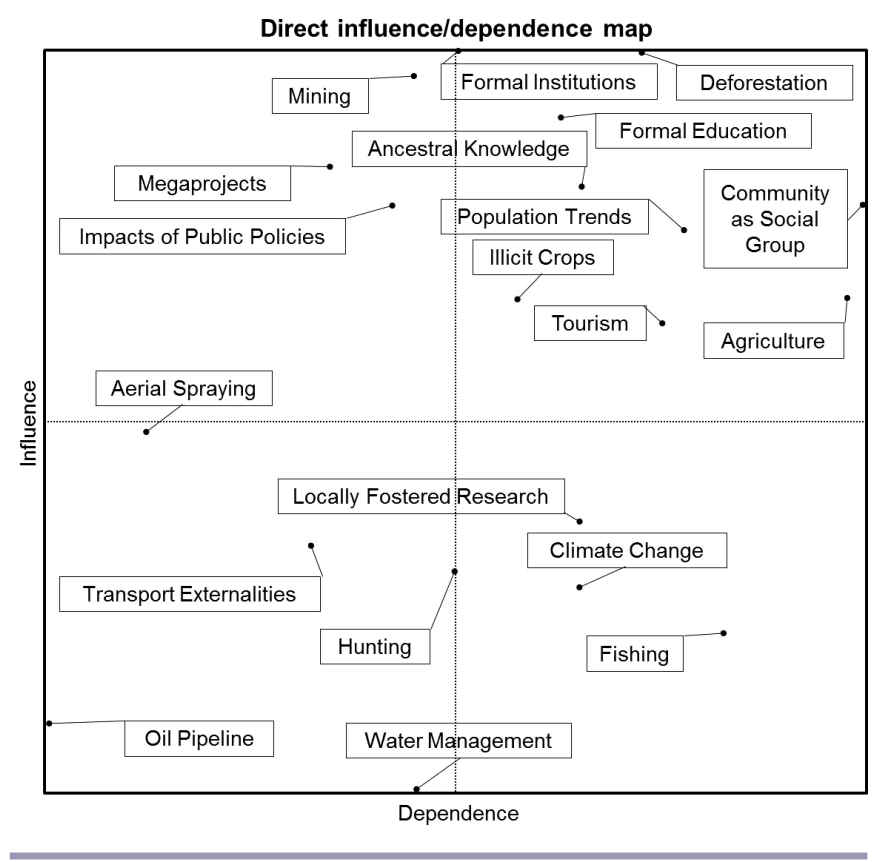


Table 3. List of variables selected in each social-ecological systems (SES).

\begin{tabular}{|c|c|c|}
\hline Colombia & Mexico & Argentina \\
\hline Population trends & $\begin{array}{l}\text { Economic activities (forestry and agriculture for } \\
\text { income) }\end{array}$ & Petrochemical Industry Pole \\
\hline Mining & Livelihoods (for subsistence) & Employment sources \\
\hline Fishing & CBNRM Nonpaid activities & Tourism \\
\hline Deforestation & Migration trends & Local markets \\
\hline Illicit crops & Political stability & External governance of fisheries \\
\hline Formal institutions & Environmental legislation & $\begin{array}{l}\text { Lack of political interest in environmental } \\
\text { sustainability }\end{array}$ \\
\hline Climate change & Monitoring and sanctioning processes & Fishermen associations \\
\hline Oil pipeline & Governance institutions & Catches \\
\hline Transport externalities & Property rights system & Seasonality of fishery and tourism \\
\hline Hunting & Collective-choice rules & Wildlife \\
\hline Agriculture & Extraction and exclusion rights & Income \\
\hline Tourism & Economic value of natural resources & History of artisanal fishery \\
\hline Megaprojects & Importance of the resources for inhabitants & Dredging and Liquefied Natural Gas Project \\
\hline Impacts of public policies & History of use & Conservation measures \\
\hline Water management & Sanitary infrastructures and services & Community networking \\
\hline Formal education & & Environmental changes in coast and estuary \\
\hline Locally fostered research & & Overfishing \\
\hline Aerial spraying & & Resource sustainability \\
\hline Community as social group & & Changes in climate patterns \\
\hline Ancestral knowledge & & Pollution \\
\hline
\end{tabular}

Fig. 6. Influence/dependence map for direct influences in Mexico.

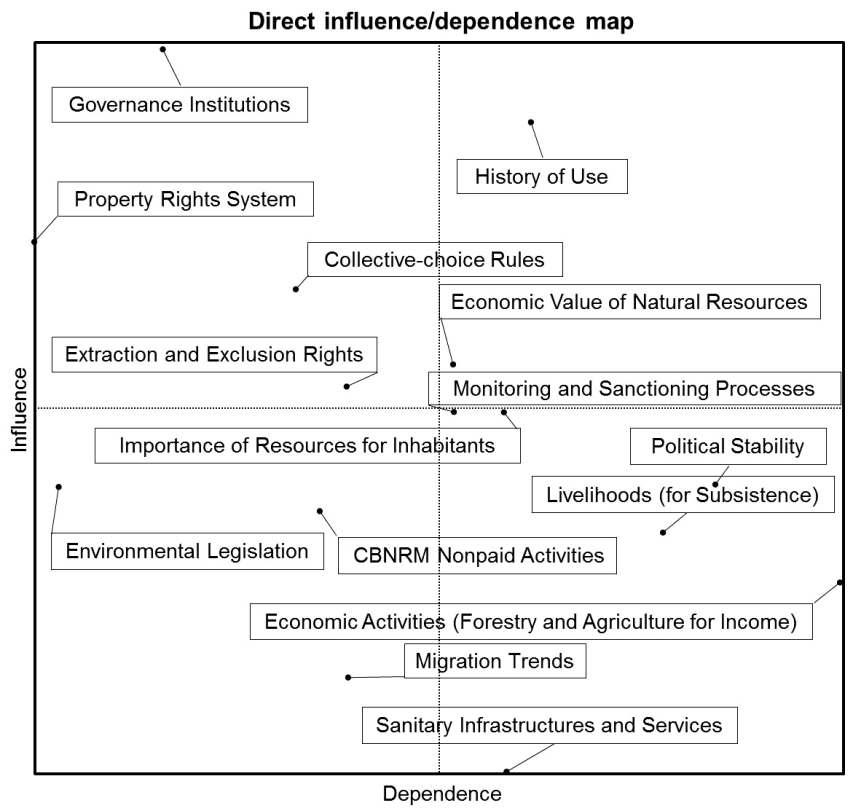

In Colombia, there were few regulators, and variables tended to concentrate as stakes (e.g., deforestation, formal education, ancestral knowledge, population trends, etc.), indicating that although these variables can be influenced by actions and policies, they also have a powerful capacity to influence other variables. Thus, the effects of actions should be carefully analyzed to avoid undesired outcomes. In Mexico and Argentina, the situations were precisely the opposite, i.e., only one stake
Fig. 7. Influence/dependence map for direct influences in Argentina.

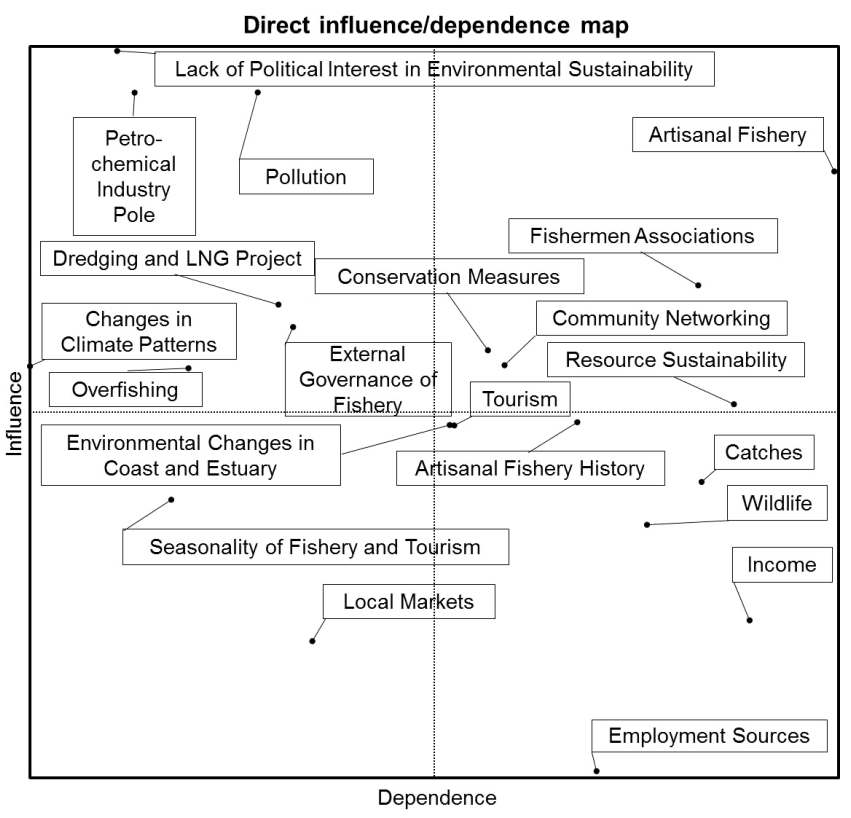

variable was identified for each country (history of use and artisanal fishery, respectively) and a greater concentration of variables were identified as regulators. This positioning is interesting because these variables can act as levers, giving actors greater influential capacity to decide which actions are necessary to move the system in their preferred direction.

Figures 8, 9, and 10 present the influence/dependence maps of indirect influences. Comparing the maps of direct and indirect 
Fig. 8. Influence/dependence map for indirect influences in Colombia.

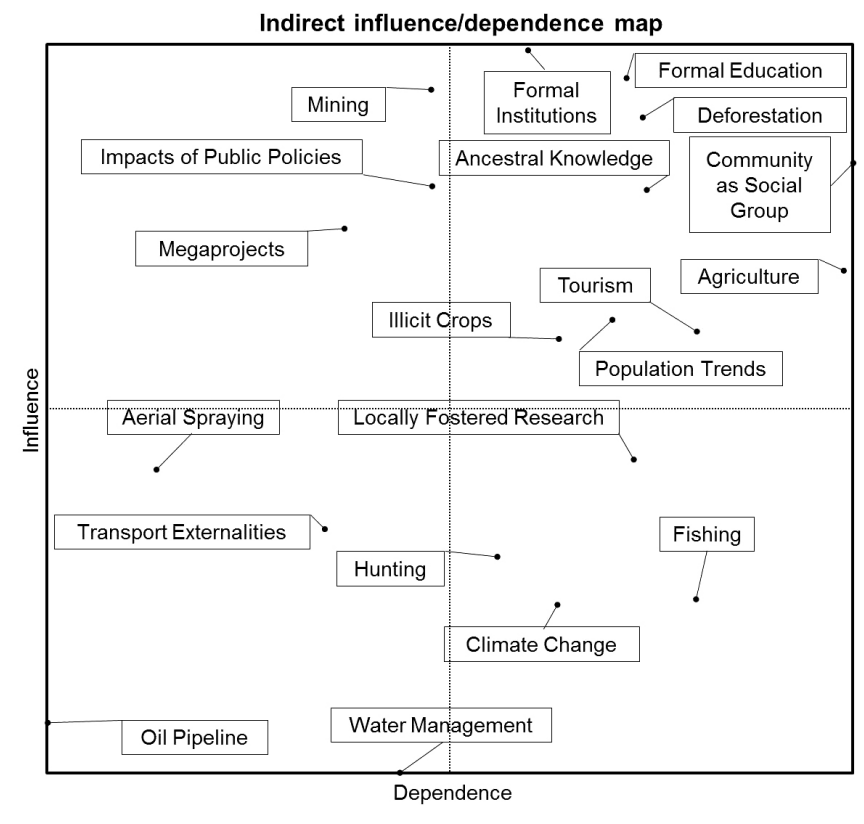

Fig. 9. Influence/dependence map for indirect influences in Mexico.

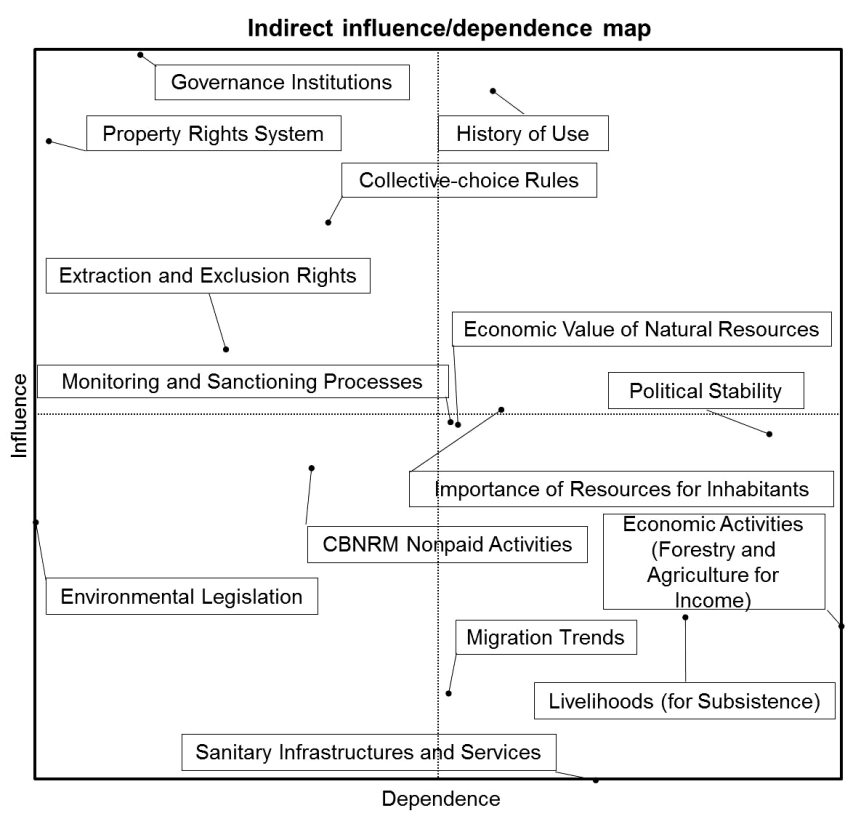

influences and how the variables can change their influence/ dependence rankings led to interesting insights regarding the system's dynamics. The evolution of the relative positions of variables might be interpreted as the potential future evolution of the SES and elucidates the roles that community members can
Fig. 10. Influence/dependence map for indirect influences in Argentina.

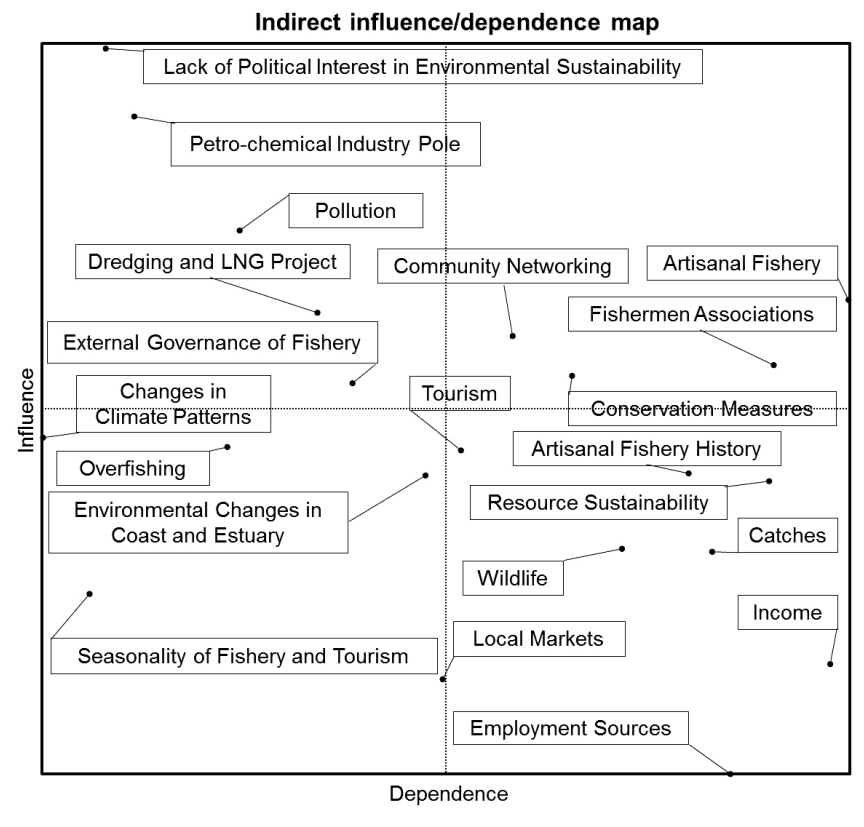

play in modeling their SES's future. Many variables have quite similar positions, but shifts in other variables reveal hidden key variables or influences. For example, in Argentina's case, the local markets variable became more dependent, showing that it was influenced by other variables; the resource sustainability variable became an output of other actions, and the overfishing variable proved to be more autonomous, indicating that internal stakeholders had few opportunities to influence its performance. In Mexico, the livelihoods and migration trends variables became more dependent; in other words, they were the result of other variables, and the political stability variable increased both in dependence and influential capacity. Finally, in the Colombian community, the population trends and ancestral knowledge variables shifted to become more dependent, and deforestation became less influential in the system's dynamics.

The networks of variables that influence one another can be visualized through influence graphs. These graphs highlight the most active nucleus of the system and help explain how different variables are interrelated, thereby providing a better understanding of how actions affecting one variable can be transmitted throughout the system. Because the MICMAC influence graphs are not user-friendly, particularly for nonexpert audiences, the Colombian team used Vensim software (http:// www.vensim.com) to present the results to community members (Fig. 11; see Delgado-Serrano et al. (2015b) for a detailed analysis of the networks of variables).

\section{DISCUSSION}

Applicability of PSA as a tool for decision making and sustainable management

Different features are identified as necessary for sustainable CBNRM, including understanding the SES's complexities; 
elucidating technical, financial, social, institutional, and political constraints (Armitage 2005); building the capacity to manage (Murphree 1993); and enhancing community members' participation and empowerment (Agrawal 1995, Reed 2008, Constantino et al. 2012). Additionally, the CBNRM approach is based on a multilevel governance system (Brondizio et al. 2009) in which some decisions are made internally, e.g., self-governance capacity (Van Laerhoven and Barnes 2014), while others depend on external institutions that require high levels of mutual understanding and collaboration between local and external actors (Armitage 2005). Other concerns include the need to recognize and legitimize local knowledge without idealizing it, and to create context-specific knowledge networks (DavidsonHunt and O'Flaherty 2007) that foster the integration of scientific and local knowledge (Raymond et al. 2010).

Fig. 11. Influence graph provided by MICMAC (top graph) and reinforcement cycles extracted using VENSIM (bottom graph) in Colombia.

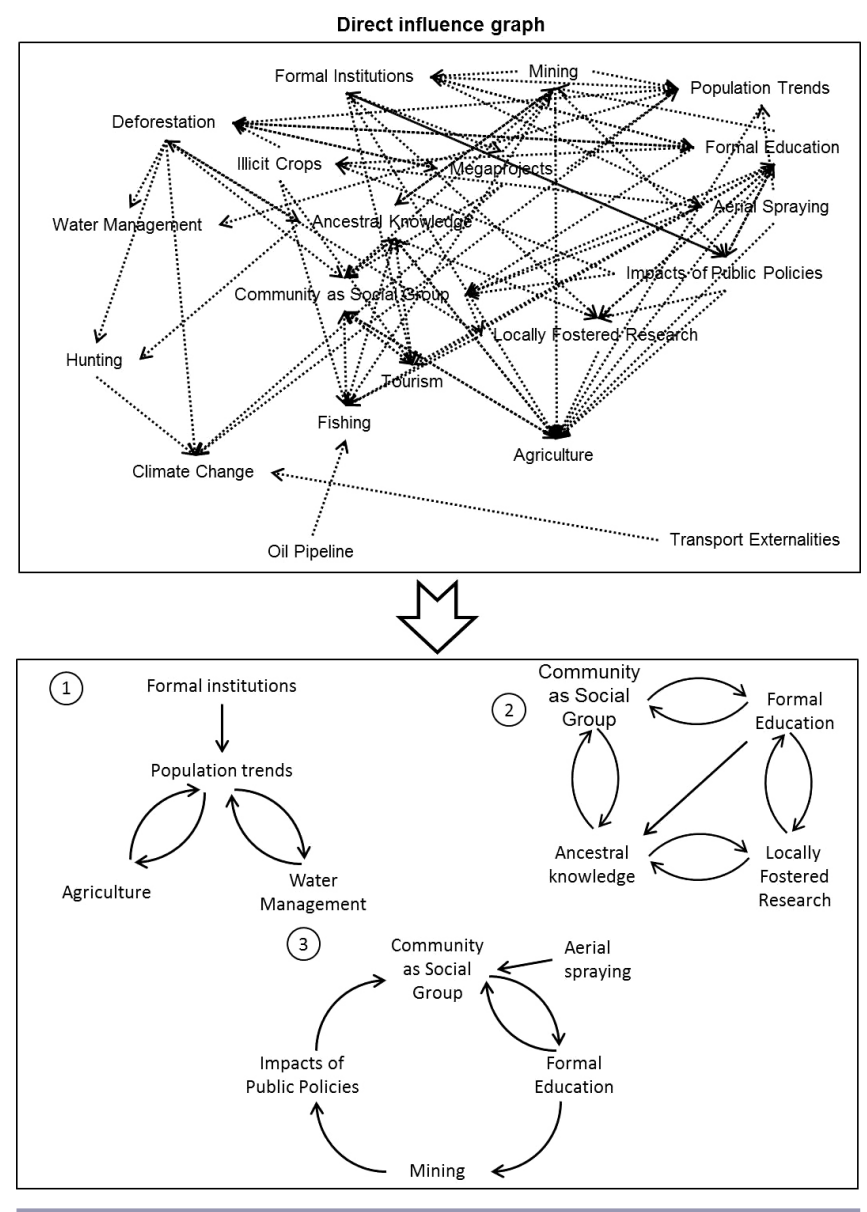

PSA matches several of these needs and supports planning and management, as a result. The multistakeholder group identified how SES work by using a method that permitted the systematic analysis of these complex systems. This method identifies not only the relevant variables but also how they interact. The capacity of variables either to influence or to be influenced informs the results of actions related to these variables. The subsystems and networks/loops of variables illuminate the reinforcement cycles. The links between social and ecological variables emphasize the intimate connections between the natural and human systems in the SES and the need to consider both in the decision-making process.

The tool addressed the inherent complexity of SES, encouraged local reflection, and produced a picture of the participants' views that detected patterns and relationships in this subjective information through mathematical analysis. By including both the local community and external stakeholders in detecting problems and discussing their possible solutions, it can contribute to empowerment (Trimble and Berkes 2013) and to building capacities for the joint management of SES. PSA also helped to structure the discussions around the dynamics of each system and, through a reflexive process, promoted consensus and shared visions among the participants, laying the foundations for a more comprehensive understanding of the SES as a whole, and reinforcing skills for natural resource management. For example, in the Colombian SES, after PSA exercise, the participants realized that ecotourism, an initiative strongly promoted by some villagers, can provide income and livelihood opportunities, but also will increase the already existing waste and sewage management problems. Thus, these issues have to be integrated in the planning of the ecotourism strategy. In the Argentine SES, the participants listened to each other and started to understand the positions of the different collectives and sectors. These discussions contributed to raise community awareness and to understand that conservation measures were necessary even if they could slow down the development expectations of some sectors. Finally, in the Mexican SES, the authorities have created a strategic analysis group, where commoners and researchers are analyzing the viability and the future perspectives of the different communal firms like the sawmill or the ecotourism facilities.

Additionally, the entire process contributed to communities' selfgovernance capacity by increasing the participants' capacity for monitoring and evaluating the results of internal and external actions on natural resources. In the Mexican case, the results of the strategic group analysis are currently being discussed at the Assembly of Commoners to make decisions on its future. The Argentine fishermen started monitoring their activities and discovered that not only trawlers influence the overfishing problems they face, but also the artisanal fishery techniques they use. Hence, they are reflecting on how to increase the sustainability of their fishing resources. Finally, the exercise increased the agency capacity of the CBNRM authorities in Colombia when they used their bargaining powers to negotiate the conditions under which the highway that crosses its territory could be built by the infrastructure company. Other advantages of using PSA to analyze SES dynamics within CBNRM contexts include the following: (1) previous knowledge of the method by the participants was not required; (2) quantitative data or data series, which are often missing in rural environments, were not needed; (3) it was easy to set up and use open-access software; and (4) it enhanced participation and communication among participants.

The method also has some limitations. As a result of its qualitative nature, subjectivity plays a fundamental role, and there is no single correct reading of the outputs because they are based on the participants' interpretations. This can lead to at least three types 
of biases. First, PSA depends strongly on participants' choices. In fact, the results can be strongly biased by the dominant views within the group (Fabricius et al. 2007, Stringer et al. 2006). Additionally, specific groups may not be interested in participating, and their views will thus be unrepresented. Furthermore, this type of bias can be intentional: if there are conflicts in the area, facilitators may try to avoid the conflicts by omitting certain participants. Second, PSA outcomes do not represent a reality but rather a means of looking at reality (Godet 1994). The group can make collective mistakes, and a consensus may not necessarily be the best possible output (London and Rojas 2015). The input data (the list of variables and MDI) provide as much information about the manner in which reality is perceived by the working group (and therefore about the group itself) as they do about the system under observation. Third, and last, facilitators can introduce other biases, such as by introducing an initial question connected to their personal research interests and not to the community members' primary concerns (e.g., in Argentina's community, stakeholders were more interested in analyzing political influence on system management than in the environmental challenges faced by the SES) or by using the results to obtain answers to their research questions.

These biases must be considered when designing exercises, but are not necessarily limitations. In CBNRM contexts, the planning and implementation of policy measures is a bottom-up process. Actions and policy making rely on the perceptions and attitudes of local actors. PSA results provide information regarding how the stakeholders perceive the system and its evolution. This knowledge is essential for identifying the problems that people observe and for designing strategies to tackle them. Future changes also depend on the decisions of local actors, and their views must be considered in any sustainable strategy. By using these techniques, the effects of different management actions addressing one or several variables within the SES can be analyzed, and their various effects evaluated; for example, the links between variables highlighted by PSA, drove participants to consider the influence of population, institutions, agriculture, and forestry when addressing the problems of waste and water management in the Colombian SES; in the Mexican case, the issues of migration and livelihood options have now induced the increase in the timber volume that will be cut and processed in the coming forest management plan. Stakeholders can identify the management plan that best fits their vision for the sustainability of the system. Furthermore, the process can be complemented by other methods, such as scenario building (see Waylen et al. 2015).

\section{Adaptations for using PSA in CBNRM contexts}

The PSA method was originally designed for highly trained participants and sectors with substantial resources. Its use in CBNRM contexts required important modifications in selecting the stakeholders, adjusting the participatory tools, and adapting the methodology to the cultural dynamics of the local communities. However, we found that these modifications jeopardized neither the technique nor the validity of the results. The environmental differences and dissimilar social interactions between the three SES allowed testing and fine-tuning of the method in different conditions and promoted broader methodological learning about issues to consider when applying this technique in CBNRM contexts.
The three communities broadly accepted the working method. The opportunity to first work separately and to later discuss the outputs with external stakeholders was received very well in Colombia and Mexico. In Colombia, 25 community members were trained as facilitators and can now independently apply PSA. In Mexico, the General Assembly appointed a semipermanent commission to attend the workshops and to learn the technique for future applications, but many of these actors became less involved. In Argentina, the exercise provided the opportunity for both internal and external stakeholders to discuss the management of their natural resources as they worked together, creating a communication platform of great value that has since been used to integrate other future policy and management actions.

One important task was adapting the scientific concepts of PSA to the communities' needs. The researchers translated the technical and abstract language to lay language (and to the participants' native language in Mexico) and used attractive and comprehensible ideas. The questions used to guide the discussions were also carefully designed (Huntington et al. 2002). Visual, e.g., drawings, pictures, etc., and oral dynamics based on the communities' cultures were used to make participants feel more confident (Agrawal 1995). At a minimum, a facilitator and a reporter were present to ensure the fluidity of the workshop and the completeness of the gathered data. The Colombian mock exercise helped to calibrate time, language, and organizational aspects and develop a guide to support the future use of the tool by communities.

The number of workshops was kept at the working minimum needed to guarantee relevant results and an acceptable level of participation. Special attention was paid to scheduling the workshops at the most convenient places, time, and periods. Aspects such as the geographic distribution of the participants, limited transportation, and labor-intensive periods were considered. To avoid participant fatigue, the sessions were not too long. However, different decisions were made for each research site, from condensing the workshops to a single day to spreading the workshop over more days to facilitate integrating participants' attendance with their daily responsibilities.

Hosting separate workshops with internal and external stakeholders was not actively promoted because the absence of direct interaction between different stakeholders can limit the sharing of different points of view and reduce cross-fertilization. However, this separation was understood as necessary because the differences in power (or other) relations would have inhibited the internal stakeholders, preventing them from fully expressing their opinions (Mayers 2005). In any case, the joint discussion of the results allowed the maximum complexity to be captured and differences in interests and views to emerge between groups. Sharing views produced interesting new insights (Bryson et al. 2002) and fostered mutual learning, i.e., the internal perspective regarding the SES tended to be very centered on daily worries and occasionally lacked breadth, whereas the external vision was missing practical knowledge.

Facilitators controlled the duration of sessions and discussion topics. Local participants frequently lack participatory arenas where they can discuss different issues, e.g., in Argentina, and thus, they can easily lose track of the objective of the meeting and focus their discussions on unrelated issues (Reed et al. 2007). However, 
flexibility is also necessary. For example, Mexican participants asked to continue the project over the next several days to have more time to reflect.

Presentation of the results was adapted to the cultures of the local communities, and the method used was explained through visual techniques or images (Luttrell and Chalfen 2010) and understandable language. The fuzzy influence charts delivered by MICMAC forced researchers to use more easily understood displays, which helped participants visualize the method's abstract concepts. In the Mexican SES, where many community members are almost illiterate and are unfamiliar with computers, facilitators transferred the results of the influence/dependence maps to colored sheets showing the variables in their respective positions, using the variables' names and a representative picture relevant to that specific community. This approach was highly welcomed by all the stakeholders and made the results substantially more comprehensible for the participants.

\section{CONCLUSIONS}

We suggest the use of PSA as a helpful tool to strengthen CBNRM. It provides information reflecting the dynamics and evolution of SES according to participants' perceptions and hence contributes to planning, management, and coping with environmental challenges. The tool enabled the integration of various actors and sources of knowledge, validating local evidence without compromising community participation. Therefore, it laid the foundation for a more comprehensive understanding of the SES as a whole and reinforced the decisionmaking process. Additionally, it fostered participation, capacity building, and local empowerment. By gathering together several stakeholders, it allowed for new social networks to be formed and new communication platforms to be created.

However, the technique consumes much time and effort because the entire basis of analysis and participation must be established in advance. In this research, the foundational work had already been undertaken, and the stakeholders were already involved. Additionally, careful monitoring and facilitation were required. The different attachments of community members to the research led to different outcomes. In Colombia, coresearchers were trained in the method and can now apply it independently with little support. In the other SES, these skills were less developed. These results showed that after an initial facilitation, community members could use the technique, paving the way for its use in other CBNRM initiatives. However, other users must be aware of these initial requirements.

Finally, we are cautiously optimistic about the future use of the technique and its potential contribution to sound sustainable management in these communities. The bases have been established and the community members have shown their agreement and confidence in the process and the results. Following the PSA exercise, some positive results have already been observed, such as the commissioning of studies on the future of communal firms and on the new forest management plan by the Mexican community; the active involvement of artisanal fishermen association in a recently approved Artisanal Fishery Act and the agreement of the different actors about the need to pass an integrated fishing and coastal management plan in the Argentine SES; and the creation of a Leadership School by the Colombian authorities to strengthen governance issues, local identity, and sound resource management. The research provided several examples of situations, actions, and decisions that reflect better capacities for sustainable management, but we cannot be sure that all of them are directly linked to PSA. However, the shifts in the approaches to CBNRM and sustainable management envisaged in the three-years' work with these communities assure us of, at least, the indirect effects of the technique. Medium and long-term monitoring of the outcomes of such actions will provide a better understanding of its effective contributions to better decisions.

Responses to this article can be read online at: http://www.ecologyandsociety.org/issues/responses. $\mathrm{php} / 8505$

\section{Acknowledgments:}

To Manolo Delgadot, whose support and inspiration made the impossible possible. This research has been financed by the Seventh Framework Program of the European Commission in the frame of the Project "Community-based management of environmental challenges in Latin America" (FP7-ENV2011-282845 COMET$L A)$. Authors are very grateful to all the researchers, community members, and stakeholders in Colombia, Mexico, and Argentina who have collaborated in this research, especially to $M^{a}$ Adelaida Farah, Diana Maya, Pablo Ramos, Bryann Avendaño, and Lina Pinzon, for their support in the Colombian methodological development and fieldwork. Authors also recognized the contributions of the anonymous reviewers and subject editors to improve the manuscript.

\section{LITERATURE CITED}

Agrawal, A. 1995. Dismantling the divide between indigenous and scientific knowledge. Development and Change 26:413-439. http://dx.doi.org/10.1111/j.1467-7660.1995.tb00560.x

Anderies, J. M., M. A. Janssen, and E. Ostrom. 2004. A framework to analyze the robustness of social-ecological systems from an institutional perspective. Ecology and Society 9(1):18. [online] URL: http://www.ecologyandsociety.org/vol9/iss1/art18/

Arcade, J., M. Godet, F. Meunier, and F. Roubelat. 1992. Structural analysis with the MICMAC method \& Actors' strategy with MACTOR method. AC/UNU Millenium Project, Washington, D.C., USA.

Armitage, D. 2005. Adaptive capacity and community-based natural resource management. Environmental Management 35:703-715. http://dx.doi.org/10.1007/s00267-004-0076-Z

Avendaño, B., M. A. Farah Q., D. L. Maya V, C. Ortiz G., L. Pinzon, and P. Ramos. 2013. Stakeholder vision on problems and drivers related to environmental challenges in Colombia case study. Community-based Management of Environmental Challenges in Latin America, Córdoba, Spain. [online] URL: http://www. comet-la.eu/index.php/en/publications.html

Benassouli, P., and R. Monti. 2005. La planification par scénarios: Le cas Axa France. Revue Futuribles 203:37-61. 
Berkes, F. 2007. Community-based conservation in a globalized world. Proceedings of the National Academy of Sciences of the United States of America 104:15188-15193. http://dx.doi. org/10.1073/pnas.0702098104

Berkes, F., J. Colding, and C. Folke. 2000. Rediscovery of traditional ecological knowledge as adaptive management. Ecological Applications 10:1251-1262. http://dx.doi.org/10.1890/1051-0761 (2000)010[1251:roteka]2.0.co:2

Berkes, F., and C. Folke. 1998. Linking social and ecological systems. Management practices and social mechanisms for building resilience. Cambridge University Press, Cambridge, UK.

Brondizio, E. S., E. Ostrom, and O. R. Young. 2009. Connectivity and the governance of multilevel social-ecological systems: the role of social capital. Annual Review of Environment and Resources 34:253-278. http://dx.doi.org/10.1146/annurev.environ.020708.100707

Bryson, J. M., G. L. Cunningham, and K. J. Lokkesmoe. 2002. What to do when stakeholders matter: the case of problem formulation for the African American Men Project of Hennepin County, Minnesota. Public Administration Review 62:568-584. http://dx.doi.org/10.1111/1540-6210.00238

Chapuy, P., and V. Gros. 2010. Collectively foreseeing future issues: prospective strategy contributes to the agriculture and food systems' 'futures studies' club. Technological Forecasting and Social Change 77:1540-1545. http://dx.doi.org/10.1016/j. techfore.2010.06.025

Constantino, P. A. L., H. S. A. Carlos, E. E. Ramalho, L. Rostant, C. Marinelli, D. Teles, S. F. Fonseca-Junior, R. B. Fernandes, and J. Valsecchi. 2012. Empowering local people through communitybased resource monitoring: a comparison of Brazil and Namibia. Ecology and Society 17(4):22. http://dx.doi.org/10.5751/ es-05164-170422

Cox, M., G. Arnold, and S. Villamayor Tomás. 2010. A review of design principles for community-based natural resource management. Ecology and Society 15(4):38. [online] URL: http:// www.ecologyandsociety.org/vol15/iss4/art38/

Davidson-Hunt, I. J., and R. M. O'Flaherty. 2007. Researchers, indigenous peoples, and place-based learning communities. Society \& Natural Resources 20:291-305. http://dx.doi. org/10.1080/08941920601161312

De Jouvenel, H., and M.-A. Roque. 1994. La catalogne à l'horizon 2010. Economica, Paris, France.

Delgado-Serrano, M. del M., M. Ambrosio-Albalá, and F. Amador. 2015a. Exploring prospective structural analysis to assess the relevance of rural territorial development in Spain and Nicaragua. Cuadernos de Desarrollo Rural 12:35-56. http://dx.doi. org/10.11144/Javeriana.cdr12-76.epsa

Delgado-Serrano, M., E. Oteros-Rozas, P. Vanwildemeersch, C. Ortíz Guerrero, S. London, and R. Escalante. 2015b. Local perceptions on social-ecological dynamics in Latin America in three community-based natural resource management systems. Ecology and Society 20(4):24. http://dx.doi.org/10.5751/ ES-07965-200424

Delgado-Serrano, M. del M., and P. Ramos. 2015. Making Ostrom's framework applicable to characterise social ecological systems at the local level. International Journal of the Commons 9:808-830. http://dx.doi.org/10.18352/ijc.567

Dietz, T., E. Ostrom, and P. C. Stern. 2003. Struggle to govern the commons. Science 302:1907-1912. http://dx.doi.org/10.1126/ $\underline{\text { science. } 1091015}$

Escalante Semerena, R. I., S. Basurto-Hernández, A. X. Cruz Bayer, E. Moreno Reyes, F. Chapela, I. Hernández-López, and Y. Lara. 2013. Stakeholder vision on problems and drivers related to environmental challenges in Mexico. Community-based Management of Environmental Challenges in Latin America, Córdoba, Spain. [online] URL: http://www.comet-la.eu/index. php/en/publications.html

European Commission. 2014. European Foresight Platform. European Commission, Brussels, Belgium. [online] URL: http:// www.foresight-platform.eu/

Fabricius, C., and S. Collins. 2007. Community-based natural resource management: governing the commons. Water Policy 9:83-97. http://dx.doi.org/10.2166/wp.2007.132

Fabricius, C., C. Folke, G. Cundill, and L. Schultz. 2007. Powerless spectators, coping actors, and adaptive co-managers: a synthesis of the role of communities in ecosystem management. Ecology and Society 12(1):29. [online] URL: http://www.ecologyandsociety. org/vol12/iss1/art29/

Flannery, T. 2006. The weather makers: how man is changing the climate and what it means for life on earth. Grove Press, New York, New York, USA.

Godet, M. 1986. Introduction to la prospective: seven key ideas and one scenario method. Futures 18:134-157. http://dx.doi. org/10.1016/0016-3287(86)90094-7

Godet, M. 1994. From anticipation to action: a handbook of strategic prospective. UNESCO, Paris, France.

Godet, M. 2006. Creating futures: scenario planning as a strategic management tool. Economica, Paris, France.

Gómez-Limón, J. A., A. Gómez-Ramos, and G. Sanchez Fernandez. 2009. Foresight analysis of agricultural sector at regional level. Futures 41:313-324. http://dx.doi.org/10.1016/j. futures.2008.11.007

Huntington, H. P., P. K. Brown-Schwalenberg, K. J. Frost, M. E. Fernandez-Jimenez, D. W. Norton and D. H. Rosenberg. 2002. Observations of the workshop as a means of improving communication between holders of traditional and scientific knowledge. Environmental Management 30:778-792. http://dx. doi.org/10.1007/s00267-002-2749-9

Kelly, R., L. Sirr, and J. Ratcliffe. 2004. Futures thinking to achieve sustainable development at local level in Ireland. Foresight 6:80-90. http://dx.doi.org/10.1108/14636680410537547

Lafourcade, B., and P. Chapuy. 2000. Scenarios and actors' strategies: the case of the agri-foodstuff sector. Technological Forecasting and Social Change 65:67-80. http://dx.doi. org/10.1016/S0040-1625(99)00128-6

Leach, M., R. Mearns, and I. Scoones. 1999. Environmental entitlements: dynamics and institutions in community-based 
natural resource management. World Development 27:225-247. http://dx.doi.org/10.1016/S0305-750X(98)00141-7

London, S., and M. Rojas. 2015. Integrating community and policy making: structural analysis and MICMAC tool. International Association for Fuzzy-Set Management and Economy (SIGEF) Conference Proceedings. Università de Girona, Girona, Spain.

London, S., M. Rojas, M. Luján-Bustos, M. A. HuamantincoCisneros, M. M. Ibañez, F. Scordo, G. M. E. Perillo, M. C. Piccolo, J. C. Pascale, G. Fidalgo, P. Bordino, L. Berninsone, M. del C. Vaquero, C. Rodriguez, M. Zilio, and M. Recalde. 2013. Stakeholder vision on problems and drivers related to environmental challenges in Argentina Case Study. Community-based Management of Environmental Challenges in Latin America, Córdoba, Spain. [online] URL: http://www.comet-la.eu/index. php/en/publications.html

Luttrell, W., and R. Chalfen. 2010. Lifting up voices of participatory visual research. Visual Studies 25(3):197-200. http:// dx.doi.org/10.1080/1472586X.2010.523270

Mayers, J. 2005. Stakeholder power analysis. International Institute for Environment and Development Power Tools, London, UK.

Millennium Ecosystem Assessment (MEA). 2005. Ecosystems and human well-being. Island Press, Washington, D.C., USA.

Murphree, M. 1993. Communities as resource management institutions. International Institute for Environment and Development Gatekeeper Series 36.

Nelson, D. R., W. N. Adger, and K. Brown. 2007. Adaptation to environmental change: contributions of a resilience framework. Annual Review of Environment and Resources 32:395-419. http:// dx.doi.org/10.1146/annurev.energy.32.051807.090348

Ostrom, E. 2007a. Sustainable social-ecological systems: an impossibility? Annual Meetings of the American Association for the Advancement of Science, Science and Technology for Sustainable Well-Being. http://dx.doi.org/10.2139/ssrn.997834

Ostrom, E. 2007b. A diagnostic approach for going beyond panaceas. Proceedings of the National Academy of Sciences of the United States of America 104:15181-15187. http://dx.doi. org/10.1073/pnas.0702288104

Ostrom, E. 2009. A general framework for analyzing sustainability of social-ecological systems. Science 325:419-422. http://dx.doi.org/10.1126/science.1172133

Parrott, L., C. Chion, R. Gonzalès, and G. Latombe. 2012. Agents, individuals, and networks: modeling methods to inform natural resource management in regional landscapes. Ecology and Society 17(3):32. http://dx.doi.org/10.5751/es-04936-170332

Raymond, C. M., I. Fazey, M. S. Reed, L. C. Stringer, G. M. Robinson, and A. C. Evely. 2010. Integrating local and scientific knowledge for environmental management. Journal of Environmental Management 91:1766-1777. http://dx.doi.org/10.1016/ j.jenvman.2010.03.023

Reed, M. S. 2008. Stakeholder participation for environmental management: a literature review. Biological Conservation

\section{1:2417-2431. http://dx.doi.org/10.1016/j.biocon.2008.07.014}

Reed, M. S., A. J. Dougill, and M. J. Taylor. 2007. Integrating local and scientific knowledge for adaptation to land degradation: Kalahari rangeland management options. Land Degradation \& Development 18:249-268. http://dx.doi.org/10.1002/ldr.777

Shackleton, C. M., T. J. Willis, K. Brown, and N. V. C. Polunin. 2010. Reflecting on the next generation of models for communitybased natural resources management. Environmental Conservation 37:1-4. http://dx.doi.org/10.1017/S0376892910000366

Soviana, S., and R. Kühl. 2013. Assessing community-based environmental management: coordination, motivation and performance. International Journal of Environment and Sustainable Development 12:86-101. http://dx.doi.org/10.1504/ IJESD.2013.051731

Stratigea, A., and C.-A. Papadopoulou. 2013. Foresight analysis at the regional level - a participatory methodological framework. Journal of Management and Strategy 4:1-16. http://dx.doi. org/10.5430/jms.v4n2p1

Stringer, L. C., A. J. Dougill, E. Fraser, K. Hubacek, C. Prell, and M. S. Reed. 2006. Unpacking "participation" in the adaptive management of social-ecological systems: a critical review. Ecology and Society 11(2):22. [online] URL: http://www. ecologyandsociety.org/vol11/iss2/art39/

Trimble, M., and F. Berkes. 2013. Participatory research towards co-management: lessons from artisanal fisheries in coastal Uruguay. Journal of Environmental Management 128:768-778. http://dx.doi.org/10.1016/j.jenvman.2013.06.032

Van Laerhoven, F., and C. Barnes. 2014. Communities and commons: the role of community development support in sustaining the commons. Community Development Journal 49: i1 18-i132. http://dx.doi.org/10.1093/cdj/bsu005

Waylen, K. A., J. Martin-Ortega, K. L. Blackstock, I. Brown, B. E. Avendaño Uribe, S. Basurto Hernández, M. B. Bertoni, M. L. Bustos, A. X. Cruz Bayer, R. I. Escalante Semerena, M. A. Farah Quijano, F. Ferrelli, G. L. Fidalgo, I. Hernández López, M. A. Huamantinco Cisneros, S. London, D. L. Maya Vélez, P. N. Ocampo-Díaz, C. E. Ortiz Guerrero, J. C. Pascale, G. M. E. Perillo, M. C. Piccolo, L. N. Pinzón Martínez, M. L. Rojas, F. Scordo, V. Vitale, and M. I. Zilio. 2015. Can scenario-planning support community-based natural resource management? Experiences from three countries in Latin America. Ecology and Society 20(4):28. http://dx.doi.org/10.5751/es-07926-200428

Wiber, M., A. Charles, J. Kearney, and F. Berkes. 2009. Enhancing community empowerment through participatory fisheries research. Marine Policy 33:172-179. http://dx.doi.org/10.1016/j. marpol.2008.05.009 